\title{
A dinâmica natural das paisagens cearenses e sua importância para o planejamento ambiental
}

\author{
The natural dynamics of Ceará landscapes and its impact on environmental planning \\ OLIVEIRA $^{1}$, Í. P.; CRUZ², M. L. B. \\ icaro256@gmail.com
}

\begin{abstract}
Resumo
Este trabalho tem como objetivo discutir a dinâmica das paisagens naturais do território cearense e sua importância para o planejamento ambiental. Foi pautada em uma revisão bibliográfica principalmente em autores que utilizam a concepção sistêmica da natureza, mas também dando destaque para os trabalhos setoriais que constituem etapa importante na análise integrada. o trabalho consiste em uma sistematização teórico-metodológica para um curso de curta duração ocorrido durante I Seminário Degradação e Recuperação Ambiental na Universidade Estadual do Ceará. Foi realizada uma breve explanação dos processos formadores das paisagens globais levando em consideração as trocas de matéria e energia dentro do sistema terra, bem como a ação dos fatores endógenos e exógenos na formação das paisagens. Tratou-se do quadro natural do Estado do Ceará e a sua importância nos projetos de Zoneamento Ambiental, com destaque para a ideia de Zoneamento Ecológico Econômico tendo como base trabalhos de autores já consagrados. Por fim, apresentou-se com base no autor acima citado as unidades geoambientais do Estado e seus respectivos graus de estabilidade, com base nas suas características naturais e no grau de conservação.
\end{abstract}

Palavras-chave: Dinâmica natural, paisagens cearenses, planejamento ambiental.

\begin{abstract}
This work aims to discuss the dynamics of natural cearense territory and its importance to environmental planning. It was based on a literature review mainly authors who use the systems view of nature, but also giving emphasis to the sector works that constitute an important step in the integrated analysis. The work consists of a theoretical and methodological systematization for a short course occurred during Seminar I Degradation and Environmental Recovery at the State University of Ceará. a brief explanation of the formation processes of global landscapes taking into account the exchange of matter and energy in the earth system, as well as the action of endogenous and exogenous factors in the formation of landscapes was held. It was the natural framework of the State of Ceará and its importance in the Environmental Zoning projects, especially the idea of Ecological Economic Zoning based on authors of works already established. Finally, he presented is based on the author quoted above the geoenvironmental units of the state and their respective degrees of stability, based on its natural characteristics and the degree of conservation.
\end{abstract}

Keywords: Natural Dynamics, Cearense Landscapes, Enviromental Planning.

\section{INTRODUÇÃO}

A terra é um sistema aberto, e portanto, há uma constante troca de matéria e energia. O sol é a principal fonte de energia deste sistema é a sua radiação que comanda os processos climáticos e definem a estruturação e dinâmica das grandes zonas climáticas do globo, influenciando na distribuição da vida pelo planeta. Também merece destaque a atuação do calor aprisionado no núcleo do planeta que ao pressionar a crosta provoca movimentos que repercutem na formação das grandes cadeias de montanhas e libera energia através do vulcanismo e do tectonismo. 
O fluxo e transformação contínua de matéria e energia faz com que o planeta esteja em constante mutação, o que se vê hoje é resultado da ação das forças internas e externas acima mencionadas. A relação dialética entre essas forças produz as paisagens naturais que são modificadas a partir da ação das sociedades ao longo dos séculos. Neste sentido, Ab'Saber (2003), define paisagem como sendo sempre uma herança de processos fisiográficos e biológicos, e patrimônio dos povos que historicamente as herdaram.

Desta relação intensa entre forças endógenas e exógenas impõem-se uma série de dinâmicas que repercutem no quadro geológico, geomorfológico e também bioclimático. Enquanto matéria organizada em instâncias mais complexas, a vida moldou-se e evoluiu conforme as mudanças ocorriam. Tais mudanças podem ser exemplificadas a partir de glaciações e interglaciações que o planeta já vivenciou e que infligiram variações nos níveis dos oceanos, alteração na circulação atmosférica, zoneamento climático e no quadro biogeográfico. O quadro ambiental da região Nordeste reflete bem esta dinâmica. Fernandes (2009), afirma que o quadro vegetacional existente hoje no Nordeste Semiárido é um padrão paisagístico de segunda ordem, visto que a vegetação que aí se instalou após o arrasamento da superfície, verificado durante todo o Terciário é bem distinta do que se tem atualmente.

A dinâmica das paisagens naturais pode ser analisada a partir de linhas ou princípios gerais, tais como o princípio do atualismo, proposto por (HUTTON, 1785; PLAYFAIR, 1802) que afirmam que as leis que regem as dinâmicas atuais são as mesmas que sempre atuaram na história do planeta, mesmo que em intensidades diferentes. Entretanto, é importante salientar que as paisagens evoluem de maneira não necessariamente semelhante e que condições mesológicas influenciam na estruturação dos ambientes provocando uma variação paisagística como por exemplo se verifica no Nordeste brasileiro, ou mesmo no contexto tropical úmido em que ocorrem.

A partir da concepção de que a natureza evolui de modo a originar paisagens distintas, as preocupações com as políticas de planejamento ambiental e ordenamento do território devem estar pautadas nas particularidades de cada ambiente, levando em consideração as potencialidades e limitações existentes a fim de serem elaborados preceitos condizentes com a realidade natural e sobretudo socioambiental.

A geografia enquanto ciência, incialmente preocupou-se com estudos voltados somente à dinâmica natural, entretanto, evoluiu metodologicamente e o que temos atualmente é uma preocupação em enxergar a dinâmica não somente como produto das relações entre forças naturais, mas como resultado também de uma atuação da sociedade que ao longo da sua história tem modificado tais paisagens. 
Nesse sentido, surgiram metodologias na geografia que tem como objetivo analisar de forma integrada a dinâmica da paisagem, levando em consideração as características naturais e sociais. Sotchava e Bertrand foram dois dos principais geógrafos que contribuíram com o tal pensamento, embora haja outros importantes.

A contribuição de tais autores está na formulação do conceito de geossistema, embora seja prudente destacar que ambos possuem características metodológicas distintas. No entanto, os dois basearam-se nos postulados da Teoria Geral dos Sistemas, proposta pelo biólogo austríaco, Bertalanffy.

Para o Estado do Ceará, Souza (2000), definiu a partir da concepção sistêmica presente em (BERTALANFFY, 1937; SOTCHAVA, 1978; BERTRAND, 1969) um esboço de zoneamento geoambiental, dividindo o território estadual em unidades de paisagem desde escalas menores, como os domínios, até escalas maiores como os sistemas e sub-sistemas ambientais. O autor, baseado no conceito de ecodinâmica de Tricart (1977), ainda avaliou o estado de conservação de cada unidade levando em consideração o balanço entre morfogênese e pedogênese, servindo posteriormente de base para a formulação de políticas de planejamento ambiental no Estado.

Assim, este artigo tem como objetivo discutir a dinâmica natural das paisagens cearenses e sua repercussão no planejamento ambiental, tendo como base uma visão holística e sistêmica. O mesmo trata-se de uma sistematização teórico-metodológica que subsidiou uma fala proferida no I Seminário degradação e recuperação ambiental: diferentes abordagens, múltiplas possibilidades ocorrido na Universidade Estadual do Ceará - UECE.

\section{METODOLOGIA}

A elaboração deste trabalho foi pautado em pesquisa bibliográfica a partir de autores que trabalham a dinâmica da natureza cearense sob o olhar sistêmico e por meio de estudos setoriais, tais como (SOUZA, 2000; SOUZA e OLIVEIRA 2006; CEARÁ, 2007; FERNANDES 2009), em experiências de campo e em trabalhos já realizados acerca das condições ambientais do território cearense.

Para a sistematização teórico-metodológica, procedeu-se inicialmente a seleção dos trabalhos acima mencionados por conterem as informações necessárias sobre a dinâmica das paisagens cearenses. Tais trabalhos encontram-se em conformidade com a concepção sistêmica da natureza, servindo portanto, de referência. Assim como, na legislação ambiental que trata do zoneamento ambiental enquanto instrumento de planejamento ambiental.

Os registros de campos já realizados em atividades ligadas aos cursos de graduação e pósgraduação da UECE serviram de apoio, para que alguns detalhes já observados em campo 
pudessem ser incluídos no trabalho. Cabe destacar os trabalhos realizados na disciplina de Geomorfologia Ambiental do curso de Mestrado Acadêmico e Doutorado em Geografia, com percurso partindo de Fortaleza até o Planalto da Ibiapaba, passando pelo Sertão Central, Sertões de Centro-Norte e Sertões Periféricos da Ibiapaba, além da porção litorânea oeste do Estado.

Nestes trabalhos, pôde-se visualizar in loco a diversidade paisagística cearense, bem como, observar a relação entre os diversos componentes naturais que dão origem a um mosaico de ambientes à medida que as condições mesológicas mudam. Como exemplo, pode-se destacar a influência da maritimidade na configuração bioclimática da planície litorânea e das Serras úmidas, ou da continentalidade junto às serras secas e depressões semiáridas. Além disso, cabe destacar modo como as comunidades se organizam infligindo mudanças nos processos e nas formas, deixando assim suas marcas e de certo modo, trazendo novas dinâmicas e cenários.

Quanto aos aspectos relacionados ao planejamento ambiental, foi utilizado como base o decreto 4.297/2002, que institui o Zoneamento Ecológico Econômico - ZEE como instrumento de planejamento ambiental e traz as diretrizes metodológicas para a execução do mesmo (Figura 1), pautado sempre em estudos que levem em consideração tanto os aspectos ecológicos quanto econômicos, para assim definir as zonas e os usos que podem ser dados à elas.

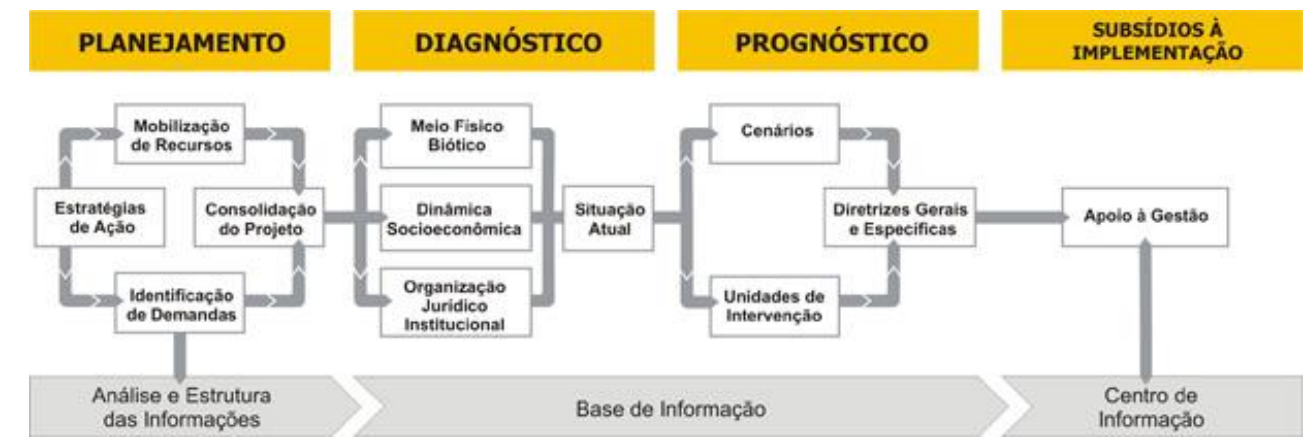

Figura 1 - Diretrizes metodológicas para elaboração do zoneamento ecológico-econômico. Fonte: Ministério do Meio Ambiente (2016)

É importante salientar que o zoneamento ambiental serve de base para tomadas de decisões que são prerrogativas do poder público e que o ZEE é apenas um dos instrumentos estabelecidos em lei para as políticas de zoneamento ambiental, existindo outros tais como, zoneamento industrial, zoneamento agrícola, zoneamento urbano, estudos de impactos ambientais etc.

Deste modo, a base bibliográfica e os registros fotográficos e anotações de campo reunidos, deram condições de elaborar um texto síntese que serviu de base para a fala proferida e já mencionada, bem como, na produção deste trabalho. 


\section{RESULTADOS E DISCUSSÃO}

A análise integrada da natureza pautada em uma visão sistêmica dos processos naturais dá condições de identificar e analisar a dinâmica e a organização dos sistemas naturais podendo a partir disto, definir potencialidades e limitações, assim como traçar cenários tendenciais por meio do que se tem na atualidade e o que se espera alcançar, conforme proposto por Souza (2009).

$\mathrm{O}$ autor acima referido, tratou da natureza cearense traçando inicialmente de um estudo de compreensão do meio tendo como base a definição dos sistemas ambientais e unidades de paisagem, passando a uma avaliação desse meio a partir da sua ecodinâmica (morfogênese e pedogênese) para assim, proceder com a estruturação do zoneamento ecológico-econômico. De modo que, desta forma ele contemplou a dinâmica das paisagens e a sua repercussão no planejamento ambiental.

\section{O contexto natural do Estado do Ceará}

Assim como a região Nordeste, o Ceará possui certa diversificação paisagística que reflete a complexidade dos processos que deram origem aos ambientes aqui encontrados. As condições de semiaridez estão presentes na maioria destes ambientes, sendo contrastados apenas por áreas de exceção representadas sobretudo, por desníveis do relevo submetidos às condições de ventos úmidos vindos do oceano.

No processo de identificação e delimitação dos ambientes, o relevo constitui-se em competente ambiental que exprime visualmente o jogo de relações que deram origem a cada um dos ambientes. Desta forma, os trabalhos utilizados aqui como referência na análise integrada da paisagem tiveram o componente geomorfológico como base na delimitação dos geossistemas ou sistemas ambientais.

Souza (1979), apresentaram os compartimentos do relevo cearense destacando a importância dos eventos ocorridos no Pleistoceno para a compreensão do quadro geomorfológico atual. Tais acontecimentos, destacam os autores, refletem bem o jogo de relações entre o arcabouço geológico, seja cristalino ou sedimentar, as condições paleoclimáticas e eustáticas assim como as condições morfogenéticas atuais.

O quadro estrutural do Ceará é representado por relevos típicos dos núcleos cratônicos e das bacias sedimentares paleomezosóicas conforme, Souza (1988). E os diferentes graus de resistências das litologias interferem diretamente na esculturação das formas, influenciando também na disposição dos elementos da exploração biológica.

O quadro geomorfológico encontra-se representado pela ocorrência mais significativa de superfícies de acumulação, planaltos e chapadas sedimentares, maciços residuais 
úmidos/subúmidos/secos e de modo mais representativo as depressões sertanejas semiáridas e subúmidas.

O contexto hidroclimático reflete bem as condições de semiaridez. No Ceará, o regime de chuva, a distribuição das precipitações no tempo e no espaço e o arcabouço geológico formado principalmente por rochas do embasamento cristalino explicam a intermitência dos rios (ZANELLA 2007). A exceção fica por conta das áreas úmidas e subúmidas dos relevos residuais pré-litorâneos, do Palanalto da Ibiapaba e do sopé da Chapada do Araripe. Já a Chapada do Apodi, apesar do embasamento sedimentar, sua baixa altitude não consegue distingui-la do contexto da semiaridez.

Nos relevos residuais próximos ao litoral e no Planalto da Ibiapaba a exposição aos ventos úmidos do oceano Atlântico propicia um mesoclima de altitude que se distingue da semiaridez. Tal condição permite a ocorrência de rios perenes ou subperenes, bem como uma maior recarga das águas subterrâneas, o que não ocorre nas áreas sob o domínio do clima semiárido. Nos planaltos e chapadas sedimentares e no substrato da Formação Barreiras no litoral, a permoporosidade dos depósitos permite a ocorrência de água subterrânea em contraponto com o que ocorre na depressão sertaneja de embasamento cristalino, cuja ocorrência de água subterrânea fica por conta das fraturas.

Um caso à parte é a Chapada do Araripe onde a porção úmida encontra-se não no platô, mas na encosta e no sopé. Tal fato se explica pela alta capacidade de absorção do arenito da Formação Santana e da disposição das camadas em direção ao Ceará. Isto contribui para que a água precipitada no topo do relevo rapidamente infiltre e ao encontrar as camadas mais impermeáveis em níveis mais baixos formem ressurgências.

Quanto à vegetação há primazia da caatinga com suas variações fisionômicas e florísticas. O quadro imposto pelo clima semiárido explica a ocorrência deste tipo vegetacional (PEREIRA E SILVA, 2007) e suas variações ficam por conta dos efeitos da maritimidade e continentalidade bem como a localização junto às encostas dos relevos úmidos e subúmidos. Em tais cenários a caatinga assume padrão arbóreo e em pontos mais elevados dá lugar à Mata Seca.

Nos maciços e planaltos úmidos a vegetação apresenta-se bem diferente do que ocorre nos sertões. Há o remanescente de mata úmida com vegetação plúvio-nebular nos topos. Essas condições se explicam pela ocorrência de maiores índices de precipitação e melhor distribuição dos mesmos no tempo e no espaço. A maior umidade também favorece o intemperismo químico e os processos pedogenéticos. Dois fatos merecem destaque. A ocorrência do carrasco no reverso imediato da cuesta da Ibiapaba a medida que a umidade que chega ao platô perde força e a ocorrência do cerradão no platô da Chapada do Araripe, onde a vegetação úmida está na encosta úmida. 
No litoral e nas porções pré-litorâneas a predominância é de vegetação sob influência da maritimidade tais como a vegetação de dunas, vegetação de tabuleiro e a vegetação típica da planície fluivo-marinha, os mangues. A vegetação de dunas desenvolve-se em terrenos arenosos e tem importância na estabilização natural destes ambientes. A vegetação de tabuleiro se assenta em terreno arenoso ou argiloso relativamente plano e onde o assentamento de áreas densamente povoadas provocaram uma forte degradação. A vegetação típica de manguezal compreende uma formação vegetal formada a partir da influência das águas marinhas e fluviais, dando origem a um ambiente de grande importância para a vida marinha.

O mosaico de solos apresenta-se variado como reflexo da variedade litológica existente no território cearense. A ocorrência da tipologia desses solos se dá também pelo contexto local observado. Como os de maior destaque podemos citar os Neossolos Litólicos dispersos ao longo dos sertões semiáridos e encostas de serras, os Argissolos que ocupam diversas unidades ambientais do Estado, desde áreas mais íngremes até relevos com ondulação suave, sendo que sua ocorrência é bem expressiva nas serras cristalinas. Também nos sertões secos, observam-se os Luvissolos e os Planossolos, sendo que este último ocorre principalmente nas áreas mais baixas correspondentes as várzeas. Nos Planaltos sedimentares há ocorrência dos Latossolos que são os solos mais antigos do Estado, exceto o que ocorre na Chapada do Apodi onde o calcário da Fomação Jandaíra deu origem aos Cambissolos. Nas planícies fluviais o destaque é para os Neossolos Flúvicos e na planície flúvio-marinha para os Gleissolos, solos típicos de manguezais.

Assim, a bibliografia pesquisada serviu de base para a síntese do quadro natural cearense acima mencionado. Esses mesmos autores e trabalhos, com destaque para (SOUZA, 2000; CEARÁ 2007), tendo a análise integrada da paisagem como suporte metodológico definiram o zoneamento ambiental do território cearense apresentado abaixo no quadro 01, onde as unidades de paisagem foram agrupadas por grau de estabilidade ambiental.

Quadro 01 - Unidades geoambientais do Ceará e seus níveis de estabilidade. Fonte: (SOUZA, 2000; CEARÁ 2007)

\begin{tabular}{|c|c|}
\hline $\begin{array}{l}\text { Grau de estabilidade dos ambientes de acordo } \\
\text { com suas características naturais e de } \\
\text { conservação }\end{array}$ & Unidades Geoambientais \\
\hline Áreas instáveis & $\begin{array}{l}\text { Superfícies de acumulação das planícies } \\
\text { lacustres, fluvio-lacustres e de inundação } \\
\text { sazonal. } \\
\text { Rebordos e patamares da Chapada do Apodi. } \\
\text { Rebordos revestidos por mata estacional da } \\
\text { Chapada do Araripe. } \\
\text { Sertões do Centro-Norte. } \\
\text { Sertões dos Inhamuns. }\end{array}$ \\
\hline
\end{tabular}




\begin{tabular}{|c|c|}
\hline & $\begin{array}{l}\text { Serras secas e vertentes subúmidas. } \\
\text { Sertões centrais. }\end{array}$ \\
\hline Áreas medianamente estáveis & $\begin{array}{l}\text { Planícies fluviais. } \\
\text { Sertões periféricos da Ibiapaba. } \\
\text { Sertões de Crateús. } \\
\text { Sertões de Quixadá. } \\
\text { Sertões } \\
\text { Viagem/Quixeramobim/Canindé. } \\
\text { Sertões do Salgado. } \\
\text { Sertões do Cariri. } \\
\text { Níveis de cimeira das serras úmidas pré- } \\
\text { litorâneas. } \\
\text { Cristas residuais e inselbergs. }\end{array}$ \\
\hline Áreas estáveis & $\begin{array}{l}\text { Tabuleiros pré-litorâneos. } \\
\text { Paltôs das Chapadas do Apodi e do Araripe. } \\
\text { Reverso imediato e rebordos úmidos do } \\
\text { Planalto da Ibiapaba e seu reverso seco. } \\
\text { Sertões do baixo Acaraú e Coreaú. } \\
\text { Sertões pré-litorâneos do baixo Jaguaribe. } \\
\text { Sertões do Choró-Pacoti. } \\
\text { Sertões úmidos do Cariri. } \\
\text { Sertões de Iguatu. }\end{array}$ \\
\hline
\end{tabular}

\section{CONSIDERAÇÕES FINAIS}

A análise integrada da paisagem figura como um competente modelo de análise dos ambientes, pois permite agregar em um mesmo plano analítico elementos naturais e sociais. Ele surgiu como contraponto à visão mecanicista da ciência positivista e tem servido de base para se compreender o quadro ambiental do planeta, dando subsídios ao desenvolvimento de políticas de planejamento ambiental e de gestão do território.

$\mathrm{Na}$ elaboração de tais estudos, o conhecimento do meio, formado pelos seus aspectos naturais e sociais deram condições de entender a dinâmica da natureza, bem como, o modo como a sociedade tem se organizado e feito uso dos bens naturais.

Desse modo, compreender, por exemplo, como uma cidade tem se expandido e como tem tratado os recursos que a natureza oferece, dá condições para a elaboração de políticas públicas voltadas ao planejamento e também à gestão do ambiente definindo assim, ações emergenciais e prevendo cenários.

No Ceará, vários estudos realizados sob este enfoque dão ideia da sua importância para a compreensão da dinâmica natural das paisagens e serviram de base para a efetivação de instrumentos das políticas de meio ambiente. Podemos citar, além do que foi apresentado nos resultados, o Zoneamento Ecológico Econômico da APA da Serra de Baturité, o Zoneamento 
Ecológico Econômico do Bioma Caatinga e Serras Úmidas no Ceará e a elaboração de Planos de Manejo de diversas unidades de conservação do Estado.

\section{REFERÊNCIAS}

AB'SÁBER, Aziz Nacib. Os dominios de natureza no Brasil: potencialidades paisagísticas. Säo Paulo: Ateliê Editorial, 2003.

BertalanfFY Ludwig Von. Teoria Geral dos Sistemas, Petrópolis, Ed. Vozes, 1975.

BERTRAND, G. Paisagem e geografia Física global: esboço metodológico. In: Caderno de Ciências da Terra, v. 13, p. 1-21. São Paulo, 1968.

BRASIL. Decreto no 4.297 de 10 de Julho de 2002.

CEARÁ. Zoneamento Ecológico Econômico do Bioma Caatinga e Serras Úmidas do Estado do Ceará. Convênio Petrobás/FCPC/SEMACE/UFC. Fortaleza, 2007.

FERNANDES, Afrânio. Fitogeografia brasileira: províncias florísticas. $3^{\text {a }}$ ed. Fortaleza: Realce editora e indústria gráfica, 2006.

NASCIMENTO, Flávio Rodrigues do; SAMPAIO, José Levi Furtado. Geografia Física, Geossistemas e Estudos Integrados da Paisagem. Revista da Casa de Geografia de Sobral. Sobral, v.6/7, $n^{\circ} 1,2004 / 2005$.

PEREIRA, R. C. M; SILVA, Edson Vicente da. Solos e vegetação do Ceará: características gerais. In SILVA, J. B da; CAVAlCANTE, T. C; DANTAS, E. W. C. (org) Ceará: um novo olhar geográfico. 2a ed. Fortaleza: Edições Demócrito Rocha, 2007.

SOTCHAVA, V. B. Por uma teoria de classificação dos geossistemas de vida terrestre. Biogeografia. São Paulo, n. 14, 1978.

SOUZA, M J N de, OLIVEIRA, V P V de. Os enclaves úmidos e sub-úmidos do semi-árido do Nordeste brasileiro. Revista Mercator, Vol. 5, No 9 (2006).

SOUZA, M J N de. Contribuição ao estudo das unidades morfoestruturais do estado do Ceará. Revista de Geologia, (1): 73-91, junho de 1988.

SOUZA, M. J. N de. Apostila de Análise Integrada do Meio Ambiente. Fortaleza, 2009.

SOUZA, M. J. N. Bases naturais e esboço do zoneamento geoambiental do estado do Ceará. In: Souza, M.J.N. Moraes J. O. de e Lima, Luiz Cruz. Compartimentação territorial e gestão regional do Ceará, Parte I. Fortaleza Editora FUNECE. 2000.

SOUZA, M. J. N. de, LIMA, F A M, PAIVA, J B. Compartimentação Topográfica do Estado do Ceará. Revista Ciência Agronômica, 9 (1-2): 77-86, dezembro de 1979.

TRICART, J. Ecodinâmica. Rio de Janeiro: SUPREN, 1977. 
VEADO, Ricardo ad-Víncula. O Geossistema: embasamento teórico e metodológico (Relatório de qualificação). UNESP: Rio Claro, 1995.

ZANELLA, M. E. As características climáticas e os recursos hídricos do Ceará. In SILVA, J. B.

$\mathrm{S}$ [et al] (orgs). Ceará: Um novo olhar geográfico - $2^{\mathrm{a}} \mathrm{Ed}-$ Fortaleza: Edições Demócrito Rocha, 2007.

\section{AGRADECIMENTOS}

Ao Programa de Pós Graduação em Geografia da UECE - PROPGEO/UECE, ao Laboratório de Geoprocessamento e Estudos Aplicados - LABGEO/UECE e à Coordenação de Aperfeiçoamento de Pessoal de Nível Superior - CAPES.

Recebido em: 14/08/2016

Aceito para publicação em: 01/10/2016 